\title{
Percepções do sofrimento psíquico: os vínculos afetivos com familiares de presidiárias
}

\author{
Perceptions of psychological distress: the affective bonds with relatives of women prisoners
}

Percepciones del sufrimiento psíquico: lazos afectivos con familiares de reclusos

Emanuele Leal da Silva ${ }^{1}$, Renata Bandeira Jardim², Karícia Lima de Freitas Bonfim³, Guilherme Alencar da Silva ${ }^{4}$, Dione da Conceição Nunes ${ }^{5}$, Dorinaldo de Freitas Cintra Junior ${ }^{6}$.

\section{RESUMO}

Objetivo: Analisar como o rompimento dos vínculos afetivos com os familiares afeta o sofrimento psíquico das presidiárias na cidade de Teresina-PI. Métodos: A pesquisa foi realizada com mulheres privadas de liberdade a mais de 2 anos presas, na cidade de Teresina-PI, mediante abordagem qualitativa, descritiva de análise de dados. Houve um esclarecimento sobre a pesquisa, as internas que concordaram, assinaram 0 Termo de Consentimento Livre e Esclarecido (TCLE). As respostas foram obtidas por um questionário sociodemográfico e uma entrevista semiestruturada, em seguida com a coleta dos dados e análise de conteúdo de Bardin L (2011). Resultados: Participaram do estudo 11 internas, na qual os resultados das respostas é a importância da família no processo do encarceramento como também uma melhor compreensão sobre os sofrimentos psíquicos das mulheres e as formas de prejuízo na saúde mental com a perca dos vínculos familiares. Conclusão: Observou-se a necessidade do tratamento das mulheres institucionalizadas nas penitenciárias e a influência disso no processo de ressocialização, como forma de auxiliar as estratégias de saúde mental e a melhoria dos relacionamentos afetivos e, consequentemente, da qualidade de vida.

Palavras-chave: Sofrimentos psíquicos, Mulheres encarceradas, Vínculos afetivos, Família.

\begin{abstract}
Objective: To analyze how the rupture of affective bonds with family members affects the psychic suffering of inmates in the city of Teresina-PI. Methods: The research was carried out with women deprived of liberty for more than 2 years imprisoned, in the city of Teresina-PI, through a qualitative, descriptive approach to data analysis. There was a clarification about the research, the internal ones who agreed, signed the Free and Informed Consent Form (TCLE). The answers were obtained by a sociodemographic questionnaire and a semi-structured interview, followed by data collection and content analysis of Bardin $L$ (2011). Results: The study included 11 internals, in which the results of the answers is the importance of the family in the process of incarceration as well as a better understanding of the psychological suffering of women and the forms of impairment in mental health with the loss of family ties. Conclusion: It was observed the need for the treatment of women institutionalized in prisons and the influence of this in the process of resocialization, as a way to help mental health strategies and the improvement of affective relationships and, consequently, quality of life.
\end{abstract}

Key words: Psychic suffering, Incarcerated women, Affective bonds, Family.

${ }^{1}$ Centro Universitário Unifacid, Teresina - PI. *E-mail: emanueleleal24@hotmail.com

${ }^{2}$ Faculdade de Enfermagem São Vicente de Paula FESVIP, João Pessoa - PB.

3Universidade Federal do Piauí, Teresina - PI.

${ }^{4}$ Faculdade Mauricio de Nassau Uninassau, Teresina - PI.

${ }^{5}$ Centro Universitário Santo Agostinho, Teresina - PI.

${ }^{6}$ Centro Universitário Saúde ABC, Santo André - S P.

SUBMETIDO EM: 3/2021

ACEITO EM: 4/2021

PUBLICADO EM: 5/2021

REAS | Vol. 13(5) | DOI: https://doi.org/10.25248/REAS.e6938.2021 


\section{RESUMEN}

Objetivo: Analizar cómo la ruptura de los lazos afectivos con los miembros de la familia afecta el sufrimiento psíquico de los reclusos en la ciudad de Teresina-PI. Métodos: La investigación se llevó a cabo con mujeres privadas de libertad durante más de 2 años encarceladas, en la ciudad de Teresina-PI, a través de un enfoque cualitativo y descriptivo para el análisis de datos. Hubo una aclaración sobre la investigación, los internos que estuvieron de acuerdo, firmaron el Formulario de Consentimiento Libre e Informado (TCLE). Las respuestas fueron obtenidas mediante un cuestionario sociodemográfico y una entrevista semiestructurada, seguida de la recopilación de datos y el análisis de contenidos de Bardin $L$ (2011).Resultados: El estudio incluyó 11 exploraciones internas, en las que los resultados de las respuestas son la importancia de la familia en el proceso de encarcelamiento, así como una mejor comprensión del sufrimiento psicológico de las mujeres y las formas de deterioro en la salud mental con la pérdida de lazos familiares. Conclusión: Se observó la necesidad de tratamiento de las mujeres institucionalizadas en las cárceles y la influencia de esto en el proceso de resocialización, como una forma de ayudar a las estrategias de salud mental y la mejora de las relaciones afectivas y, en consecuencia, la calidad de vida.

Palabras clave: Sufrimiento psíquico, Mujeres encarceladas, Lazos afectivos, Familia.

\section{INTRODUÇÃO}

Durante muito tempo, o papel das mulheres na sociedade era pautado na execução das atividades maternas e conjugais, destinadas, exclusivamente, aos serviços do lar, educação dos filhos e dominação do companheiro. No decorrer dos anos, a mulher ascendeu seu papel participativo na sociedade, alcançando espaços que, anteriormente, eram ocupados prioritariamente por homens. Com isso, também, houve participação das mulheres em práticas antes vistas, apenas, pelo sexo masculino como o tráfico de drogas (GUSMÃO MAJ, et al., 2019). Segundo o departamento penitenciário nacional (INFOPEN, 2017) as mulheres que está sob ambiente penitenciário, geralmente é constituída por jovens com baixa escolaridade, mães solteiras, que muitas vezes é responsável pelo sustento familiar.

O Brasil ocupa com maior frequência o quarto país de maior população carcerária no mundo. Com isso houve um grande aumento do gênero feminino atrás das grades. Este aumento se relaciona, principalmente, pelo envolvimento com tráfico de drogas que, de modo geral, coloca a presença da mulher na criminalidade a partir de uma postura de coadjuvante, de cúmplice dos homens, ou pela autoria de crimes passionais (SANTORO ERA e PEREIRA ACA, 2018).

Diante desse aumento da mulher presa torna o tema da saúde no sistema prisional, um dos mais importantes debates na definição de prioridades de pesquisa na Saúde Coletiva, pela situação de encarceramento vivida que evidencia a presença de graves problemas (SOARES-FILHO MM e BUENO PMMG, 2016).

Segundo a Organização mundial da saúde (OMS), ao chegar no sistema prisional há uma exposição dessa mulher, podendo ser exposta a violência e condições de vulnerabilidade, que podem ser grande fator de risco para a saúde das mesmas. Por esses fatores expostos acima se faz necessário uma compreensão acerca do aprisionamento feminino para contribuir com um melhor entendimento (BRASIL, 2005).

Desse modo, se faz necessário uma compreensão acerca do aprisionamento feminino para contribuir com um melhor entendimento sobre a precarização do encarceramento feminino no Brasil, levando em consideração que tal processo produz uma segunda punição às mulheres, o abandono sofrido por parte da família, como também, os sofrimentos psíquicos. O percentual aumento do encarceramento feminino, acrescido ao abandono das mulheres na prisão, foram utilizados no presente artigo como fatores de análise das relações de gênero (LOPES KM, 2015).

A relevância científica deste estudo se embasa pelos poucos estudos sobre a inserção da mulher no crime. Além disso, há ainda o problema da insuficiência de dados e indicadores nos bancos de dados oficiais do 
governo que forneçam informações importantes sobre o perfil da mulher em situação de prisão e as consequências sobre essa situação (ALMEIDA VP, 2016). A relevância social deste estudo consiste em fornecer um olhar mais empático diante das mulheres privadas de liberdade e um despertar aos profissionais que trabalham nas instituições responsáveis a fim de propiciar um atendimento qualificado e articulado, entre os diversos níveis de proteção social e as demais políticas, reforçando a importância das políticas sociais para que as mulheres privadas de liberdade possam gozar de seus direitos, como também a população no todo, assim como, a criação de políticas públicas mais voltadas para esse público (SANDORO AER e PEREIRA ACA, 2018).

Diante do exposto, o objetivo deste estudo foi analisar como o rompimento dos vínculos afetivos com os familiares afeta o sofrimento psíquico das presidiárias na cidade de Teresina-PI.

\section{MÉTODOS}

Tratou-se de uma pesquisa qualitativa, descritiva, de análise de dados. A pesquisa foi realizada na cidade de Teresina- PI em uma Penitenciaria Feminina no período de setembro há outubro de 2020, com uma amostra por conveniência que foi composta por 11 detentas, com duração da coleta de dados de cada participante de aproximada 40 minutos. Tinha como critérios de inclusão do estudo são: mulheres em condição de encarceramento por período maior a 2 (dois) anos, sem distinção de faixa etária. Foram desconsideradas para fins de pesquisa mulheres que tenham algum tipo de transtorno mental ou alguma limitação, além de pessoas que não tinham nenhum tipo de ligação com a família antes de ser presa, como também as que não tinham interesse em participar da pesquisa.

Os instrumentos utilizados para obtenção dos dados foram a entrevista semiestruturada e um questionário sociodemográfico. As questões foram elaboradas pela pesquisadora, baseando-se na temática de investigar e descrever os sofrimentos psíquicos das mulheres presas frente a perda dos vínculos afetivos familiares, como também compreender a avaliação que as pessoas fazem sobre sua vida, na qual irá direcionar para a mulher sob ambiente penitenciário.

O trabalho foi submetido ao Comitê de Ética e Pesquisa (CEP) da Faculdade Integral Diferencial (UNIFACID/WYDEN), através da plataforma Brasil, depois da aprovação para a realização da pesquisa por meio do protocolo CAEE. 35011420.9.0000.5211 e o Parecer consubstanciado No. 4.276.474 da plataforma Brasil. Em seguida, foi iniciada a coleta dos dados seguindo os aspectos éticos das resoluções 466/12 e 510/16 do Conselho Nacional de Saúde (CNS), as quais regulamentam as pesquisas realizadas com seres humanos em prol da proteção a dignidade, liberdade a autonomia humana (BRASIL, 2012; BRASIL, 2016).

Os resultados foram utilizados preservando-se o sigilo, a privacidade e a autonomia das participantes. As mesmas assinaram o Termo de Consentimento Livre e Esclarecido (TCLE). Foram esclarecidos todos os riscos e incômodos que o estudo poderia a vim causar, como também, o sigilo das informações prestadas por elas e o direito de tirar o consentimento a qualquer tempo e sem qualquer ônus.

Após a coleta, os dados foram organizados em tabelas de acordo com as orientações da Análise de Conteúdo propostas por (BARDIN L, 2011), no qual, foram criadas categorias temáticas. Essas categorias têm a ver com as informações que mais se repetem nas respostas dos participantes e que formam categorias onde os discursos que se encaixam serão elencados e, a partir disso, cada sentença será analisada a partir do significado da teoria em questão, a fim de encontrar respostas subjetivas dos participantes, demonstrando a personificação do assunto abordado e a manifestação distinta existente.

\section{RESULTADOS E DISCUSSÃO}

A idade mínima das participantes foi de 21 anos e a máxima foi de 41 anos, com desvio médio e desvio padrão de $(M=32,09 ; D P=5,41)$. Destas $72,73 \%$ afirmaram serem solteiras; $81,81 \%$ afirmaram ter apenas 0 ensino fundamental incompleto. $54,55 \%$ das detentas são de classe baixa a e $18,18 \%$ de classe média. $90 \%$ delas frequentam algum tipo de religião. De acordo com as 11 participantes entrevistadas $90,90 \%$ são reincidentes, todas as participantes afirmaram serem domésticas. 
Estes dados são corroborados segundo o Levantamento Nacional de Informação Penitenciárias de Mulheres (INFOPEN, 2017) que afirma que a maior parte das mulheres privadas de liberdade possuem baixa escolaridade, são jovens, solteiras com filhos e renda familiar precária. Além disso, não possuem estabilidade trabalhista, pois, desempenhavam ocupações de baixa qualificação, como o trabalho doméstico ou outros. Através das análises das entrevistas e levando-se em consideração o referencial teórico, os objetivos e o problema de pesquisa, surgiram cinco categorias que foram dispostas na Tabela 1 evidenciada abaixo, consolidando as questões propostas aos participantes, pois abrangem elementos importantes para a discursão dos dados da pesquisa, que serão discutidas a seguir.

Tabela 1 - Categorias encontradas na análise de conteúdo.

\begin{tabular}{lc}
\hline Categorias & Participantes \\
\hline Representações dos vinculos familiares para a mulher encarcerada & 11 \\
\hline $\begin{array}{l}\text { Os sofrimentos psiquicos causados pelo distanciamento dos vinculos } \\
\text { familiares }\end{array}$ & 11 \\
\hline $\begin{array}{l}\text { Prejuizos na qualidade das relações familiares no processo do } \\
\text { encarceramento }\end{array}$ & 9 \\
\hline $\begin{array}{l}\text { Estrategias de enfretamento das mulheres encarceradas para } \\
\text { lidar com o distaciamento familiar }\end{array}$
\end{tabular}

Fonte: Silva EL, et al., 2021.

\section{Representações dos vinculos familiares para a mulher encarcerada}

Segundo Romildo P e José S (2017) a família é considerada um grupo primário, no qual, o ser humano tem seu primeiro vínculo e constitui o espaço de construção dos valores e da própria educação. É na família que o sujeito desenvolve suas primeiras experiências como ser pertencente de uma sociedade. Além disso, é esta a instituição responsável pelo apoio físico, social e emocional.

A família se apresenta como um fator determinante na saúde da mulher privada de liberdade, além de facilitar o processo de encarceramento pelo qual está se passando, como também, a ressocialização, através do suporte afetivo e social a mulher. Isto pode ser percebido nas seguintes falas a seguir (JESUS A, et al., 2015).

“[...] O apoio familiar ajuda muito, só em você saber que não está só na caminhada, por que é uma caminhada, você sabendo que tem a família perto você tem mais força, motiva muito é dar força resistência para suportar muita coisa aqui dentro" (sujeito 1).

"[...] Ajuda muito, se não fosse eles eu não suportaria [...] E muito mais difícil, a pessoa sem o apoio da família nesse lugar, fica doido" (sujeito 5).

"[...] Com certeza, porque muita gente que eu vejo que a família pouco liga são as pessoas que sofrem mais aqui dentro, desde financeiro ao saber que tem alguém por ti, e saber que tem alguém que se preocupa por ti” (sujeito 9).

Nos discursos das detentas se percebe à família como fundamental não somente para dar suporte afetivo, mas também financeiro como na fala da participante 9 . Sendo como forma de sustento dentro da prisão fornecendo matérias de limpeza, higiene pessoal, medicamentos, uma alimentação diferente das fornecidas pela penitenciaria, como também marcação de consultas no lado externo, são alguns dos procedimentos que a família faz pelo seu familiar que se encontra presa diante da situação precária observada no sistema carcerário é confirmada pelo acentuado número de comorbidades existentes na população carcerária as quais apresentam suscetibilidade às doenças (LOBO L, et al., 2019).

Santin G e Klafke TE (2017), fala que a família ocupa um lugar indispensável para a garantia da sobrevivência e da proteção integral dos membros. É a família que geralmente propicia os aportes afetivos e, sobretudo materiais necessários ao desenvolvimento e bem-estar dos componentes, dando força e palavras de apoio aos problemas que venha a existir na vida do ser humano. Do exposto e possível observar a fala da participante 7 quando afirma: 


\author{
'Dar força, dar palavra de conforto me ajuda bastante. Mudou muita coisa a força \\ que eles me dão a ajuda dando palavras para vencer" (sujeito 4).
}

$\mathrm{Na}$ fala da participante 1, pode-se perceber que família desempenha um papel importante para conseguir pagar a pena dentro do sistema penitenciário, visto que é um ambiente complexo, com vários problemas existentes, como convívio com o desconhecido, os procedimentos da penitenciaria e um ambiente muitas das vezes inadequado. A partir das análises realizadas, foi possível perceber nas falas das participantes a grande importância da família na prisão, se fazendo importante trabalhar dentro do sistema prisional assuntos como carinho, afetividade, amor e respeito familiar, sendo de grande valia para este processo. Ao perceber o afeto familiar, pode ter maiores condições de lidar com a sua situação atual, como também, com o processo de ressocialização. Ficando mais confiantes para Ihe dar com os problemas existentes na prisão, evidencia-se a importância da família na ressocialização das presas, na manutenção da qualidade de vida e da saúde mental.

\title{
Os sofrimentos psiquicos causados pelo distanciamento dos vinculos familiares
}

Segundo Constantino P, et al. (2016) as pessoas que se encontram presas apresentam mais sofrimentos psicológicos do que a população em geral, devido as condições precárias encontradas nas penitenciarias, como a superlotação, a insalubridade do ambiente e a pouca quantidade de profissionais para atender as demandas. Assim, Silva AJN, et al. (2019) afirmam que a vulnerabilidade psicossocial e os problemas sociais podem elevar o desenvolvimento do sofrimento psíquico e comprometimento funcional associado ao sofrimento mental. Esse fenômeno e observado nas elucidações a seguir:

“[...] Então eu tento me desligar o máximo possível lá de fora pra eu poder puxar minha cadeia normal. Por que quando bate a saudade pesa, a gente fica triste, chora, fica angustiada" (sujeito 1)

"[...] E um sentimento ruim, o pior sentimento é a saudade" (sujeito 4).

"[...] E muito ruim, cada dia que se passa a saudade aumenta mais, a tristeza a vontade de estar perto deles. Dói dentro da gente" (sujeito 6).

A taxa de suicidio entre presas e 20 vezes maior do a média nacional. São muitos são os fatores que influenciam o sofrimento psicológico atrás das grades. Entre eles, está a falta de informação sobre a situação prisional e o tempo da pena, a violência física e emocional a que são submetidas e o abandono e o distanciamento da família e dos amigos. Podendo ser uma fonte inesgotável de angústia (CHAVES KB, 2018).

Mesmo tendo muitas das vezes compreensão da situação, elas ainda sofrem e sentem pesar pela situação vivida dentro da prisão. Podemos perceber isso na fala da participante 2, quando ela expressa na sua fala 0 sofrimento psicológico sofrido pelo distanciamento familiar:

"Já pensei em me suicidar não vou mentir, estar distante da família e insuportável".

Nesse sentido, foi possível identificar sentimentos como sensibilidade, tristeza, angústia, alteração do padrão de sono, uso indevido de medicação psicotrópico, interrupções das relações familiares, causando sensação de abandono, ficando mais suscetíveis a crises de ansiedade, automutilação, depressão, podendo ter pensamentos e comportamentos suicida (SANTOS MV, et al., 2017).

O uso excessivo e descontrolado de medicamentos como antidepressivos e ansiolíticos é justificado como formas de ofertar esperança e alívio às pressões do cárcere, às ausências de visitas familiares, ao próprio isolamento social e, também, como maneira de torná-las mais toleráveis à privação da liberdade e do sofrimento existente (LEITE SN, et al., 2020), como ilustra a participante 3:

"Eu sofro muito, tomo diariamente remédios para conseguir suportar a prisão e o distanciamento com minha família, não é fácil".

Mediante o exposto apresentado acima, pode-se observar que são muitos os sofrimentos psicológicos advindos do distanciamento familiar provocado pela prisão, causando vários impactos na vida das mesmas. Falam como e difícil não receber visita, e os sentimentos que isso causa, como abandono, falando sobre o 
que sentem mais falta na família dentro da prisão, e os motivos que levam a família muitas das vezes não irem visitar.

\section{Prejuizos na qualidade das relações familiares no processo do encarceramento}

O impacto nocivo da privação de liberdade atinge de forma direta a presa, como também, a sua família. Todo o sistema familiar é afetado em relação ao declínio da situação financeira, podendo haver o rompimento das relações de amizade e de vizinhança, o enfraquecimento dos vínculos afetivos, problemas na escolaridade dos filhos e perturbações psicológicas decorrentes da percepção de exclusão social (SILVA AHM e SANTOS CCC, 2004).

Gusmão MAJ, et al. (2019) apontam que as causas que levam ao distanciamento dos vínculos familiares dentro da prisão são inúmeras, tais como: a dificuldade socioeconômica dos familiares, dificuldades de deslocamento devido ao afastamento das penitenciárias, como também, a responsabilidade do cuidado dos filhos das mulheres aprisionadas, papel geralmente assumido pelas avós. Além disso, percebe-se o constrangimento nas visitas pela associação dos crimes cometidos pela detenta aos seus familiares. Isto pode ser percebido nas seguintes falas a seguir:

"[...] Eles não vêm onde eu estou devido os meus erros e tudo, não recebo visita" (sujeito 3).

"[...] Mudou muito, como eu disse só quem ainda vem me visitar e meu esposo que eu conheci quando já estava presa, minha família não vem. Eles se cansaram" (sujeito 4).

"[...] A minha mãe não vem por causa da distância, minha família e do Pará. Ela já veio quatro vezes, mas é difícil, ela cuida do meu filho de 4 anos" (sujeito 9).

"[...] Minha família toda desestruturada, meu marido tinha arrumado emprego junto comigo e foi despedido e ele acabou pagando por uma coisa que não tinha nada haver" (sujeito 8).

A literatura aponta que aqueles os quais se relacionam diretamente com o individio apenado sofrem refleexões de tais penas,como preconceitos advindo da sociedade por culpalizar a familia pelos crimes da detenta, como também o cansaço da familia sobre os erros da apenada. É possivel observar na fala das participantes 3 e 4 .

Segundo Jesus ACF, et al. (2015) diante da prisão a família se vê em uma nova situação: Como, por exemplo, garantir a sobrevivência dos demais membros, lidar com os problemas de revolta dos filhos, preconceito da sociedade em relação à família de preso e às normas e imposições da própria prisão, visto que a família acaba sendo inserida no jogo de poder das práticas prisionais. Geralmente, as mulheres possuem maior dificuldade de absolvição entre a própria família acerca dos crimes, como também o constrangimento da família vivenciar a situação atual da detenta, e os procedimentos que tem que passar nas visitas, fazendo muitas das vezes a família não irem a visita, isto pode ser percebido na fala da participante 10:

\footnotetext{
"Meus filhos não vem até aqui por causa dos procedimentos que tem que passar, eles so vieram uma vez e choraram muito, então só minha mãe que vem as vezes, $e$ muito triste".
}

Muitos momentos da vida normal são perdidos enquanto o indivíduo vive no estabelecimento carcerário. O filho, geralmente sofre com a ausência da mãe na sua filha, e mãe também por estar perdendo as fases do desenvolvimento do filho, como ilustra a participante 9:

"Meu filho está crescendo longe de mim, quando fui presa ele não tinha nem 1 ano de idade, hoje já tem 4 anos, já fala, anda e está na escola e eu não pude acompanhar nada disso". 
Lopes KM (2015) discorre que, ao ser presa, a recuperação dos vínculos das mulheres encarceradas com seus filhos pode ser bastante complexa, uma vez que, os espaços de produção da vida cotidiana, durante a prisão, podem ter sido desorganizados, tendo perdas afetivas e identitárias na vida destas mulheres. Assim, é bastante comum que o espaço deixado por essa mulher seja modificado tendo, como exemplo, os filhos que precisam ser cuidados por outras pessoas, o que pode dificultar a construção e manutenção dos vínculos afetivos que marcam as relações familiares e, até mesmo, o próprio espaço doméstico.

Pode-se se notar vários os motivos que prejudicas a ligação da família com as detentas dentro do aprimoramento, como dificuldades de locomoção, condições socioeconômicas, excesso de responsabilidades da família apôs a prisão da detenta, como também os julgamentos existentes. citando como e difícil não receber visita, e os sentimentos que isso causa, como abandono., falando sobre o que sentem mais falta na família dentro da prisão, e os motivos que levam a família muitas das vezes não irem visitar.

\section{Estratégias de enfrentamento das mulheres encarceradas para lidar com o distaciamento familiar}

Barbosa MGM, et al. (2021) fala que as mulheres encarceradas buscam pela superação das experiências de sofrimento, construindo diariamente, estratégias de enfrentamento para adaptarem-se à institucionalização prisional e aos seus desdobramentos. Os fragmentos das falas a seguir mostram o desenvolvimento de traços de resiliência diante das adversidades do cárcere:

\section{"[...] Procuro superar essa vida do presídio através do trabalho, tento não ficar parada" (sujeito 4) \\ "[...] eu lembro que minha família está bem ai eu volto ao normal" (sujeito 8) \\ "[...] E difícil, se a gente não tiver um foco, saber que vai acabar, uma hora vai acabar pra retornar e tem pessoas Ihe esperando lá fora e o que vai a gente aguentar" (sujeito 9)}

Segundo Porto PN, et al. (2019); a religião e uma das mais comuns estratégias de enfrentamento para sair do ócio, ouvir palavras de conforto, e é um momento em que a interna tem a possibilidade de ter contato com pessoas de fora da instituição penal estar atrelado ao fato de que a religião propicia uma vivência em comunidade que pode funcionar como uma rede de apoio social. Pode-se perceber na fala da participante 7 , a importância da religião como estratégia adaptativa dentro do sistema prisional:

"Eu não me desespero porque tenho fé em Deus, toda vez que o inimigo tenta me puxar para uma depressão".

Assim como a importância da utilização da mão de obra carcerária, que ajuda na redução de pena, como também tem como objetivo criar uma autodisciplina, ressocializar e sair do possível tedio do aprisionamento, como também forma de reinserção social (ALMEIDA PRC, et al., 2016).

A família volta como ponto importante nas estratégias para conseguir pagar a pena não só ajudando como estratégia para suportar a vida na prisão, como apoio emocional e a confirmação que a presa não está sozinha, como também ajuda a detenta nas formalidades do processo penal, como contato com advogados, defensores públicos, assim tendo o sentimento de que não estar sozinha. É possível identificar as estratégias nas falas das participantes.

A partir das análises realizadas é possível identificar a importância do trabalho dentro do sistema, e da fé que muitas das vezes e adquirida após a prisão, como estratégias de enfrentamento. É perceptível nos recortes das falas das participantes sobre a relação afetiva bastante significativa com os seus familiares, se fazendo como pontos estratégico para lhe dar com processo do encarceramento.

\section{CONCLUSÃO}

Com base nos achados encontrados no presente estudo foi possível identificar que a perda dos vínculos familiares e um fator determinante para o surgimento de sofrimentos psíquicos das mulheres encarceradas, dificultando no processo do encarceramento, assim como os prejuízos advindo da prisão frente aos laços 
afetivos com os familiares. Esses achados indicam também a necessidade de um maior investimento no sistema prisional, no sentido de ampliar e qualificar os serviços de saúde mental, com o intuito de fornecer a essa parcela da população um tratamento adequado, com especial ênfase ao atendimento à mulher encarcerada. Nesse sentido, a estratégia de fortalecimento de vínculos familiares nas unidades prisionais, além de um direito a ser assegurado, configura-se como um fator de prevenção dos agravamentos de problemas emocionais.

\section{REFERÊNCIAS}

1. ALMEIDA PRC, et al. Condição de saúde de mulheres privadas de liberdade: uma revisão integrativa. Revista Brasileira de Ciências da Saúde, 2106; 19(1): 73-80.

2. ALMEIDA VP. Repercussões da violência na construção da identidade feminina da mulher presa: um estudo de caso. Psicologia: ciência e profissão, 2006; 26(4): 604-619.

3. BARDIN L. Análise de conteúdo, 2011, Edições 70, p. 229.

4. BRASIL. Conselho nacional de saúde. 2012, Resolução $n^{\circ} 466$. Aprova diretrizes e normas regulamentadoras de pesquisas envolvendo seres humanos. Brasília, Diário Oficial da União.

5. BRASIL. Conselho nacional de saúde. 2016, Resolução $n^{\circ} 510$, Diário Oficial da União.

6. BARBOSA MGM, et al. Dados de saúde de mulheres em regime prisional em Teresina, Piauí. Revista Eletrônica Acervo Saúde, 2021; 13(6): 5256.

7. BRASIL. Defensoria Pública do Estado de São Paulo. Núcleo Especializado de Situação Carcerária. Direitos e Deveres das Mulheres Presas. Disponível em: http://www.defensoria.sp.gov.br/dpesp/Repositorio/30/Documentos/cartilha-mulherpresa. Acesso em: 14 de abril de 2021.

8. BRASIL. Ministério da Justiça e Segurança Pública. Levantamento Nacional de Informações Penitenciárias: INFOPEN. Brasília, DF, 2017a

9. BRASIL. Ministério da Saúde. Secretaria de Atenção à Saúde. Plano Nacional de Saúde no Sistema Penitenciário. Brasília, DF, 2005

10. CONSTANTINO $P$, et al. O impacto da prisão na saúde mental dos presos do estado do Rio de Janeiro. Ciência \& Saúde Coletiva, 2016; 21(7): 2089-2100.

11. CHAVES KB. Atendimento Psicológico às Mulheres Presas. Transitando pela Psicologia Jurídica no Sistema Prisional, 2018; 12(23): 7280.

12. GUSMÃO MAJ, et al. Dinâmicas sociais, familiares e vulnerabilidades de mulheres Privadas de liberdade. Revista Saúde e Pesquisa, 2019; 12:1: 159168.

13. JESUS ACF, et al. O significado e a vivência do abandono familiar para presidiárias. Ciência \& Saúde, 2015; 8(1): 19-25.

14. LOBO LMGA, et al. Vulnerabilidade feminina para infecções sexualmente transmissíveis durante visita íntima. Revista Eletrônica Acervo Saúde, 2019; 11(8): 653.

15. LOPES KM. Noções sobre responsabilidades femininas e cuidado familiar em um grupo de mulheres encarceradas. Clínica \& Cultura, 2015; 4(1): 71-78.

16. LEITE SN, et al. Estudos de utilização de medicamentos: uma síntese de artigos publicados no Brasil e América Latina. Ciência e saúde coletiva, 2020; 13(79): 802.

17. PORTO PN, et al. Fatores associados ao envolvimento de gestantes com álcool e outras drogas. Revista Eletrônica Acervo Saúde, 2019; 11(12): 795.

18. ROMILDO P, JOSÉ S. A família e a formação de valores. Revista Batista Pioneira, 2017;6(2): 2316-686.

19. SANTIN G, KLAFKE TE. A família e o cuidado em saúde mental. Barbarói, 2017, 34.

20. SANTORO AER, PEREIRA ACA. Gênero e prisão: O encarceramento de mulheres no sistema penitenciário brasileiro pelo crime de tráfico de drogas. Meritum, 2018; 13(1): 87-112.

21. SANTOS MV, et al. Saúde mental de mulheres encarceradas em um presídio do Estado do Rio de Janeiro. Texto \& Contexto, 2017; 26(2): 5980015.

22. SILVA AJM et al. As implicações dos contextos de vulnerabilidade social no desenvolvimento infantojuvenil: da família à assistência social. Revista pesquisas e praticas psicossociais. 2019; 14(2): 2799.

23. SILVA AHM, SANTOS CCC. Medida Socioeducativa de Privação de Liberdade: uma análise do uso das tecnologias como ferramenta facilitadora da ressocialização do adolescente em conflito com a lei. Ctrl, II congresso sobre tecnologias na educação, 2017.

24. SOARES-FILHO MM, BUENO PMMG. Demografia, vulnerabilidades e direito à saúde da população prisional brasileira. Ciência \& Saúde Coletiva, 2016; 21(7): 1999-2010. 